\title{
THE EFFECTS OF A LOW-CARBOHYDRATE HIGH-FAT DIET AND PHYSICAL EXERCISE ON TYPE 2 DIABETIC PATIENTS: A REVIEW
}

\author{
Gerrit Jan Breukelman', Cornelia Johanna Du Preez², \\ Trayana Djarova-Daniels ${ }^{3}$, Albertus Kotze Basson ${ }^{3}$
}

1. Department of Human Movement Science, University of Zululand, KwaDlangezwa, South Africa;

2. Department of Consumer Sciences, University of Zululand, KwaDlangezwa, South Africa;

3. Department of Biochemistry and Microbiology, University of Zululand, KwaDlangezwa, South Africa;

\begin{abstract}
Diabetes is a worldwide health problem and is prevalent in both developed and developing countries. Type 2 diabetes is characterized as being insulin resistant with inadequate insulin response to maintain a normal concentration of glucose in the blood. It is estimated that Type 2 diabetes accounts for 90-95\% of all diabetes. Type 2 diabetes can be described as a chronic and progressive disease, caused by a combination of resistance to insulin action and impaired insulin secretion, where obesity and overweight, due to excess body fat with fat distributed in the upper body are the main complications of insulin resistance. With the dramatic increase in obesity, low-carbohydrate, high-protein, high-fat diets have become increasingly popular. Diets limiting the amount of carbohydrate intake have been called low-carbohydrate or very-low-carbohydrate, high-protein, high-fat, Banting and ketogenic diets, and are characterized by $50 \mathrm{~g}$ or less carbohydrates per day. High fat low carbohydrate diets have been found to be different from the traditional diets of most cultures. Recent studies however show that there are potential benefits associated with reducing carbohydrates and increasing fat intake. Low-carbohydrate diets have become very popular for weight loss. Although they may improve some metabolic markers, particularly in Type 2 diabetes mellitus, they seemingly have an effect on body weight, glycemic control and cardiovascular risk factors as well. Research shows that by reducing aerobic exercise capacity; poor glycemic control, increase in cardiovascular risk and elevated glycosylated hemoglobin (HbAlc) are common with Type 2 diabetics. Aerobic exercise capacity and glycemic control in Type 2 diabetes can be improved by being physically active. Regular physical activity along with diet therapy provides health benefits and has been found to be essential for primary and secondary prevention of most metabolic disorders.
\end{abstract}

Key words: Type 2 diabetes, low-carbohydrate high-fat diet, physical exercise, glycosylated hemoglobin (HbAlc) \& cholesterol

\section{INTRODUCTION}

Diabetes is a worldwide health problem and is prevalent in both developed and developing countries (Parker et al., 2002; Ahmed \& Goldstein, 2006; Psaltopoulou et al., 2010; Hjelm \& Mufunda, 2010; Dube et al., 2015; Peter \& Sabina, 2016). This metabolic disorder can be categorized into four groups, namely Type 1, Type 2, gestational and other specific origins, but the most common are Type 1 and 2 diabetes. Type 1 can be described as insulin dependent or having a defect in insulin secretion, whereas Type 2 is described as the inability to use insulin. Gestational diabetes is that which has been diagnosed during pregnancy and other specific origins tend to be due to genetic defects and/or are drug induced (ACSM, 2014; Peter \& Sabina, 2016). Combined, Type 1 and 2 currently affects more than 366 million people which is calculated to be around $7 \%$ of the world's population. This number is expected to increase to 522 mil- 
lion people by 2030 and further to 592 million by 2035 (Dube et al., 2015; Peter \& Sabina, 2016). It is also estimated that by then, $77 \%$ of people living with diabetes will come from low- and middle-income countries, and most deaths will occur before the age of 60 years (Mayosiet al., 2009; Dube et al., 2015).

Type 1 diabetes, which accounts for 5 to $10 \%$ of all diabetic infections, is characterized by a precise auto-immune destruction of the insulin-secreted $\beta$-cell in the pancreatic islets, and other cases are idiopathic in origin. Absolute insulin deficiency and high ketoacidosis are the prime characteristics of Type 1 diabetes (Ahmed \& Goldstein, 2006; ACSM, 2014). Type 2 diabetes is characterized as being insulin resistant with an inadequate insulin response to maintain a normal concentration of glucose in the blood (Kahn, 1994; Parker et al., 2002). It is estimated that Type 2 diabetes accounts for $90-95 \%$ of all diabetic infections (Ozougwu, 2013; Peter \& Sabina, 2016). According to Wild et al., (2004), Africa, as a continent, has approximately 14.7 million people living with Type 2 diabetes. This calculates to be in the area of $16.3 \%$ of the continental population. In 2013, the International Diabetes Federation (IDF) estimated that there were 3 million people living with diabetes in South Africa, with a prevalence of $8.27-9 \%$ among the age group of $20-79$ years (Bertram et al., 2013; Murphy et al., 2015; Dube et al., 2015). The development of Type 2 diabetes has been found to reduce responses of target tissues of the skeletal muscle adipose tissue axis (contracting muscle, cardiovascular system and adipocytes) to insulin (Kahn, 1994; Parker et al., 2002). Type 2 diabetes can be described as a chronic and progressive disease, where obesity and overweight due to excess body fat distributed in the upper body are the main complications of insulin resistance (Druet et al., 2006; Reaven, 2011; Ozougwu, 2013; Peter \& Sabina, 2016). The American Diabetes Association and World Health Organization endorse using $\mathrm{HbA} 1 \mathrm{c}>6.5 \%$ to diagnose for diabetes, but most diagnostic methods are based on elevated fasting glucose above $\geq 126$ $\mathrm{mg} \cdot \mathrm{dL}^{-1}$ or $6.99 \mathrm{mmol}$. L-1 (ACSM, 2010).

It is well known that the pancreas is composed of two different types of tissue, exocrine acini ducts and endocrine islets of Langerhans (McArdle et al., 2007). Seventy-five percent of the islets are $\beta$-cells that secrete insulin and about $20 \% \alpha$-cells that secrete glucagon and a peptide called amylin. Insulin regulates glucose entry into the body's tissues, except the brain tissue (McArdle et al., 2007; Turcotte \& Fisher, 2008). When glucose is transported into the cells, it combines with a carrier protein on the cells plasma membrane. This way, the metabolism of glucose can be regulated by insulin. Glucose is stored as glycogen in skeletal muscle for later use or synthesized to triacylglycerol if not immediately catabolized for energy (Jueet al., 1989; Shulman et al., 1990; McArdle et al., 2007). If insulin is absent, only a very small amount of glucose will enter the cell. Following a meal, insulin is released from the $\beta$-cells of the pancreas to transport glucose that is released into the blood stream to the muscle cells, causing a decrease in blood glucose level. By reducing the blood glucose concentration, insulin exerts a hypoglycemic effect. Blood glucose concentration will then increase with insufficient insulin secretion (McArdle et al., 2007).

\section{METHOD}

\section{Inclusion Criteria}

The inclusion criteria for this review were (a) patients that were diagnosed with Type 2 Diabetes; (b) Type 2 Diabetic patients that used low-carbohydrate high-fat diets and Type 2 Diabetic patients using prescribed diets; (c) Type 2 Diabetic patients that engage in physical activity; (d) low-carbohydrate high-fat diets on glycated hemoglobin (HbA1c) levels; and (e)low-carbohydrate, high-fat diets on cholesterol (total cholesterol, chylomicrons, very low-density lipoprotein cholesterol 
[VLDL-C], low-density lipoprotein cholesterol [LDL-C], and high-density lipoprotein cholesterol [HDL-C]); and (f) available studies done and completed in English.

\section{Data Sources}

Keyword searches identified articles from Research Databases: MEDLINE (1976 -), Science Direct (2010 -), and Human Kinetics (2003 -). The keywords used to identify the articles used in this review were Type 2 diabetes, glycosylated hemoglobin (HbAlc) and cholesterol. Each of these searches was combined with low-carbohydrate high-fat diet and physical exercise, to identify articles that will best suit this review.

\section{Exclusion}

The exclusion criteria for this review were a) Type 1 diabetes, diet and physical exercise, b) juvenile diabetes, c) gestational diabetes, diabetic complications, high intensity exercise and training protocols. We conducted 250 searches, out of which we identified 130 articles according to the inclusion criteria relevant to this review.

\section{DISCUSSION}

\section{Type 2 Diabetes}

As previously discussed, Type 2 diabetes is insulin resistant with inadequate insulin response to maintain a normal concentration of sugar in the blood (Kahn, 1994; Parker et al., 2002; Ahmed \& Goldstein, 2006). The term insulin resistant, characterized by Type 2 diabetes, can be defined as an overproduction of insulin from the pancreas when blood glucose rises due to digestion and absorption of highglycemic carbohydrates. A diet high in simple sugars and refined carbohydrates facilitates body fat accumulation in individuals who are insulin resistant (McArdle et al., 2007).

The majority ( $80 \%$ ) of people living with Type 2 diabetes have been found to be obese at onset, with obesity significantly contribut- ing to insulin resistance (Durstine \& Moore, 2003). The establishment of optimal macronutrient distribution for weight loss diets has not yet occurred, but in the context of energy restriction, successful weight loss has been shown to be achieved with a diet low in fat or a diet low in carbohydrates (Sacks et al., 2009; Foster et al., 2010). A range of energy intake from dietary carbohydrate and fat has been recommended, with the only limitation being saturated fat intake of less than 10\% (Eckel et al.,2014). However, according to Abeteet al., (2010), a diet higher in carbohydrate has been found to have an increase in cardiometabolic risk factors which include hyperinsulinemia, especially if the carbohydrates are mainly from highly refined foods. An observation was made that individuals who were insulin resistant or secreting higher levels of insulin, lost more weight in response to a lower carbohydrate diet compared to a lower fat intake (Cornier et al., 2005; Pittas et al., 2005).It has also been observed that with an increase in energy consumption and a decrease in physical activity, the prevalence of obesity and Type 2 diabetes increases (ACSM, 2014).

South Africa, which is described as an upper-middle income economy country, is ranked $28^{\text {th }}$ largest economy in the world and the largest and most developed in Africa (SAMLRH, 2014). Economic development and urbanization lead to changes in lifestyle such as a decrease in physical activity, poor eating habits and an increase in obesity. As a result, there has been a rise in the prevalence of diabetes (Belue et al., 2009; Whiting et al., 2011; Awotidebe et al., 2016). Approximately 17 million visits related to hypertension and diabetes are made annually to clinics of the Department of Health in South Africa (Murphy et al., 2015). South Africa holds the second largest number of Type 2 diabetic people in subSaharan Africa (Mendenhall \& Norris, 2015). With recent studies it has been estimated that there is a $13.1 \%$ diabetes prevalence among 
urban African black people in the Western Cape Province and a $14.1 \%$ diabetes prevalence among urban African black women in Soweto in the Gauteng Province, both among the low-income groups in South Africa (Mayosiet al., 2009; Peer et al., 2012; Crowther \& Norris, 2012; Mendenhall \& Norris, 2015). Living with Type 2 diabetes increases the risk of cardiovascular disease (CVD) and premature death (Rydén et al., 2013; Rossen et al., 2015). An increased risk of coronary heart disease, stroke, renal failure, progressive development of specific complications of vascular disorders, retinopathy with potential blindness and disability are all associated with long term effects of Type 2 diabetes (Kawai, 2016; Awotidebe et al., 2016). According to Mendenhall \& Norris (2015), if there is an increase in diabetes, there are higher chances of developing other conditions, including mental illnesses, such as depression and infectious diseases in addition to diabetes. The increase in obesity worldwide is a problem with different challenges and in need of urgent attention. It is well known that with increased weight, Type 2 diabetes is more prevalent (ACSM, 2014).

\section{Low-Carbohydrate High-Fat Diets and Type 2 Diabetes}

According to Nordmann et al., (2006), at any given time in the United States there are approximately $45 \%$ women and $30 \%$ men that are attempting to lose weight, using diet as a major contributor, with numerous diets promoting weight loss. The most popular and recommended diets for weight loss and management according to leading medical research societies, have been found to be a high-carbohydrate, low-fat, energy deficit diet (Krauss et al., 1996; Foster et al., 2003). It has also been noted that in some subjects where diets resulted in weight loss, a decrease and prevention of Type 2 diabetes, improvement in hypertension control and even a reduction in cardiovascular morbidity and mortality has been seen (Avenell et al., 2004). Despite these efforts, obesity has doubled in the past 20 years (Flegal et al., 2002; Foster et al., 2003). With the dramatic increase in obesity, low-carbohydrate, high-protein, high-fat diets have become increasingly popular (Foster et al., 2003). Diets limiting carbohydrate intake have been called low-carbohydrate or verylow-carbohydrate, high-protein, high-fat and ketogenic diets, and they are characterized by $50 \mathrm{~g}$ or less carbohydrates per day (Volek \& Westman, 2002). It is also noted that not all very-low carbohydrate diets are necessarily high-protein diets as some are high in fat. In South Africa, the low-carbohydrate high-fat diet is commonly referred to as the Banting diet, named after the first person who used the low-carbohydrate high-fat diet, William Banting (Noakes et al., 2013). Low-carbohydrate high-fat diets are a controversial topic in the world of nutrition these days (Noakes et al., 2017). When we look at dietary guidelines over the past decade, they have stated that dietary fat should be minimized and only enjoyed on occasion (Lamont et al.,2016). In contrast to recent studies, this has been seen to be the total opposite. When exploring these diet options, it is found that both diets have pro's and con's. High fat low carbo hydrate diets have been found to be far different from the traditional diets of most cultures. Recent studies however show that there are potential benefits associated with reducing carbohydrates and increasing fat intake (Merino et al.,2014). Low-carbohydrate diets have become very popular for weight loss. Although they may improve some metabolic markers, particularly in Type 2 diabetes mellitus (Merino et al.,2014), they seemingly have an effect on body weight, glycemic control and cardiovascular risk factors as well (Noakes et al., 2017). Evidence found from clinical and preclinical studies shows that lowcarbohydrate high-fat diets lower the risk factors for cardiovascular diseases by lowering elevated blood glucose, insulin, triglyceride, ApoB and saturated fat concentrations in the body, reducing LDL cholesterol molecules, 
glycated hemoglobin (HbA1c) levels, blood pressure and body weight. At the same time, increasing HDL-cholesterol concentrations and reversing the effect of non-alcoholic fatty liver disease may also be beneficial to patients with atherogenic dyslipidemia and insulin resistance (Noakes et al., 2017). Low-carbohydrate diets with a high protein and fat intake are significantly associated with a decreased risk of Type 2 diabetes in women (Nanri et al.,2015). According to Noakes et al., (2017), it is beneficial to use low-carbohydrate highfat diets, due to the combination of the favorable adaptions in the body and the lowering of these risk factors. Benefits seen when using a low-carbohydrate diet, compared to a hypocaloric balanced diet, are decreased basal serum insulin levels, enhanced loss of water, enhanced dissolution of glucose reservoirs, and increased total energy expenditure owing to increased thermal effects of food and feeling full after meals. There is also a limited food variety making it easier to know what to eat and what not to eat (Steinberger et al., 2003; Bravata et al., 2003; Mithieux et al., 2005; Demol et al., 2009). Fat, in particular, is high in calories per $100 \mathrm{~g}$ compared to other macro-nutrients, but fat is metabolized at a much slower rate, thus keeping a person fuller for longer and reducing the amount of food eaten throughout the day, and in the long run lowering calorie intake.

\section{Exercise and Type 2 Diabetes}

Research has shown that a reduced aerobic exercise capacity and poor glycemic control is common with Type 2 diabetes, and that, with an increase in cardiovascular risk in Type 2 diabetes, elevated glycosylated hemoglobin (HbAlc) are found (Wei et al., 1999; Wei et al., 2000; Unwin et al., 2010; Zhang et al., 2012; Revdal et al., 2016). According to Boulé et al., (2003), aerobic exercise capacity and glycemic control in Type 2 diabetes can be improved by regular exercise. Benefits associated with aerobic exercise are found to be greater than simply the lowering of glucose levels, but an improvement in overall morbidity and cardiovascular risk status (Wei et al., 2000; Church et al., 2005; Revdal et al., 2016). Even though there are so many benefits and health improvements gained by exercise training, two out of three people living with Type 2 diabetes do not exercise regularly and also do not meet the recommended exercise guidelines (Thomas et al., 2004; Colberg et al., 2010). The current recommended exercise guidelines for Type 2 diabetes is moderate to vigorously intensive aerobic physical activity for 150 min per weekspread out over at least 3 days and 2-3 days per week of moderate to vigorous resistance training (Colberg et al.,2010; Rossen et al., 2015). According to Umpierre et al., (2011), there is a dose-response associated with an even greater decline in $\mathrm{HbA1c}$ and a reduction in cardiovascular diseases and all-cause mortality in patients with diabetes by increasing the recommended exercise guidelines beyond the 150 min per week of moderate to vigorous aerobic activity. One of the main reasons or excuses given for not engaging in exercise in Type 2 diabetics is that they do not have time to engage in physical activity (Korkiakangas et al., 2009). It seems that the only way to improve the $\mathrm{VO}_{2 \max }$, glycemic control and other cardiovascular risk factors is to think out of the box and offer alternative methods that will be less time consuming but still effective.

Increasing the number of footsteps, a person takes per day seems to be beneficial, as it has been found that 3-4 days of 10,000 steps/ day meets the energy expenditure guidelines for the week (Tudor-Locke et al., 2011). According to Krumm et al., (2006), there is a linear relationship between body mass index (BMI) and steps taken, where women who took between 5000 - 7500 steps/day had a significantly lower BMI compared to women who took less than 5000 steps/day. It was also indicated that women who took between 7500 
- 9999 steps/day had a significantly lower BMI compared to the women who only took between 5000 - 7500. No significant difference was found in BMI between women who took more than 10,000 steps compared to those who took between $7500-10000$ steps/ day. In line with the U.S. public health guidelines, incorporating at least 30 minutes, or between 3000 - 4000 steps (out of the 7000 -10000 steps/day) of brisk walking, is recommended in promoting any step-based activities when focusing on time spent on moderate to vigorous physical activity (MVPA) (TudorLocke et al., 2011). The use of pedometers by the general public has been noted to be more likely, due to their relatively low cost, practicality and ease of interpretation (Tudor-Locke et al., 2011). The use of pedometers has been found to increase physical activity levels and improve metabolic parameters in patients with diabetes (Bravata et al., 2007; De Greef et al., 2010; De Greef et al., 2011; Rossen et al., 2015). The advantage of using a pedometer is that it motivates people to be more active, as they can monitor their steps/day, which is important for metabolic control (De Greef et al., 2011; Greaves et al., 2011). Physical activity has been found to be one of the best strategies for improving metabolic management for people that have inherited genetic tendencies that promote the development of insulin resistance and for people living a weight gaining lifestyle (Katzmarzyk et al., 2003; Conn et al., 2007; Turcotte \& Fisher, 2008). Increasing energy output by exercising for $150 \mathrm{~min} /$ week, and by decreasing energy intake by $450 \mathrm{kcal}$, has been found to be more effective than taking medication in preventing or delaying the development of insulin resistance in obese and Type 2 diabetic persons (Knowler et al., 2002; Conn et al., 2007). Improvement in insulin sensitivity in healthy, obese and Type 2 diabetic persons was found for several hours and up to a few days after just one exercise session, but significant decreases of insulin sensitivity was also noted when physical activity was not per- formed for a few days (Dela et al.,1992; Turcotte \& Fisher, 2008). Even short durations of physical activity per day can be described as a critical component of the treatment modality, especially combined with a calorie restricted diet for people living with obesity and Type 2 diabetes. Activity for at least $150 \mathrm{~min} /$ week or at least $3 \mathrm{~d} /$ week, with no more than 2 consecutive days of physical inactivity has been recommended for improvement of insulin sensitivity (Haskell et al., 2007; Turcotte \& Fisher, 2008).

It has been recommended that people with an increased risk of developing Type 2 diabetes should follow a combination of regular physical activity and a diet to reduce the onset of diabetes (Pronk \& Remington, 2015). The return to normoglycemia and management of diabetes has been seen following a combination of physical activity and diet programs. These programs commonly focus on a decrease in body weight and fat percentage. Regular physical activity along with diet therapy provides health benefits and has been found to be essential for primary and secondary prevention of most metabolic disorders (Donnelly, 2009; Kawai, 2016). According to León-Muñoz (2013), people who are consistently unfit, have an increased mortality rate compared to those whose physical activity level has been increasing over time. Diseases such as atherosclerosis with coronary ischemia have been observed as a latent disease with diabetes and obesity, hence the importance of encouraging exercise in all patients diagnosed with diabetes and obesity (Sigal et al., 2006; Kawai, 2016). Structured aerobic training has been found to be beneficial as a management technique for Type 2 diabetes therapy, as it has the ability to increase glucose uptake and improve insulin sensitivity (Santos et al., 2008; Winnick et al., 2008; Turcotte \& Fisher, 2008; Harrison et al., 2016). Using large muscle groups such as quadriceps and hamstrings has been found to stimulate glucose uptake, which 
increases energy expenditure, glucose transportation and glucose tolerance (Santos et al., 2008; Harrison et al., 2016).

\section{Low-Carbohydrate High-Fat Diets and Glycated Hemoglobin (HbA1c)}

Glycated hemoglobin (HbAlc) has been used as a key monitoring factor in the management of diabetes, as it relates to the development of long-term diabetes complications (Kuenen et al., 2011). It is often used as a primary target in the treatment of diabetes, when a calculation of the average glycaemia is done over several months. Calculations should be done every 3 months as recommended by the American Diabetes Association, to determine whether a patient has reached and maintained this glycemic goal (Tien et al., 2016). A reduction of $14 \%$ in myocardial infarction, $37 \%$ in microvascular complications and $21 \%$ in diabetes-related death has been noted by the UK Prospective Diabetes study for each 1\% reduction in HbA1c (Stratton et al., 2000). Seasonal changes, some physiological endocrine factors, environmental factors and social events, have been found to contribute to the fluctuation in HbA1c levels (Chen et al., 2004; Dasgupta et al., 2007; Gikas et al., 2009). Women with Type 2 diabetes were found to be susceptible to increased HbA1c levels with elevated temperatures (Carney et al., 2000). The cornerstones of Type 2 diabetes management have been found to be weight control, diet and exercise. Improvements of glycemic control and reduction of diabetic-related complication strategies that enhance weight loss and ideal weight maintenance are needed (Watson et al., 2015). Failure to maintain blood glucose control in patients with Type 2 diabetes by using drug therapies often happens after several years (Haimoto et al., 2008). According to Haimoto et al., (2008), a new type of diet therapy is required for treating and maintaining Type 2 diabetes - one that is easier and more acceptable to patients and are free of calorie calculations. Carbohydrate-rich grains and limiting of saturated fats and cholesterol are described as a conventional diet for Type 2 diabetes (Haimoto et al., 2008). Studies from the 1960s contradict the conventional diet for treating and maintaining Type 2 diabetes, as it was found that in Greenland and Alaska, where dietary habits favored a high-fat, protein diet with a low-carbohydrate intake, only $0.19-0.96 \%$ of the population were diagnosed with diabetes (Bang et al.1976; Haimoto et al., 2008). Furthermore, dietary protein and fat have little effect on blood glucose concentrations, which are largely dependent on the ingestion of food containing carbohydrates (Gannon \& Nuttall, 2004; Mc Auley et al., 2005; Boden et al., 2005). According to Miller et al., (2011), a diet lower in glycemic index is associated with a reduction in $\mathrm{HbAlc}$ in diabetic patients. Gannon et al., (2003), noted a similar trend, by using a high-protein, lowcarbohydrate diet, where a beneficial effect on postprandial blood glucose and HbA1c levels in diabetic patients was found. Research on low-carbohydrate diets on glycemic control in Type 2 diabetes is limited (Mc Auley et al., 2005; Boden et al., 2005; Daly et al., 2006). Studies focused more on weight loss and serum lipids (Katan, 2006; Krieger et al.,2006; Nordmann et al.,2006; Krauss et al.,2006). According to Haimoto et al., (2008), even decreasing carbohydrate intake in conventional diets from $60 \%$ to $45 \%$, causes a decrease in both HbA1c levels and BMI. Greater weight loss has been found by using a low-carbohydrate diet compared to a low-fat diet, despite similar energy intakes (Yancy et al.,2004; Mc Auley et al., 2005; Katan, 2006; Krieger et al.,2006). Greater weight loss can be due to lower postprandial insulin release with restricted carbohydrate intake in carbohydrate-reduced diets (Gannon \& Nuttall, 2004; Boden et al., 2005). HbA1c and a reduction in cardiovascular diseases and all-cause mortality in people with Type 2 diabetes has been found to be reduced by exercising for longer periods (2-3 months) (Boulé et al., 2003). Training for 150 minutes 
or longer per week at moderate intensity is prescribed to decrease HbAlc (Umpierre et al., 2011).

\section{Low-Carbohydrate High-Fat Diets and Cholesterol}

Total Cholesterol is another important factor. It is known that cholesterol is used to aid cell membrane anabolism, synthesis of adrenal gland hormone, sex hormones, vitamin $\mathrm{D}$ and secretion of bile that helps with digestion (McArdle et al., 2007). Cholesterol helps transport fat through the blood vessels, as it cannot bind to water. A protein substance binds to cholesterol before it enters the bloodstream, and these cholesterol protein packages are known as lipoproteins (McArdle et al., 2007). Lipoproteins are composed of cholesterol, phospholipids, triglycerides and protein known as apoprotein which are involved in transporting lipids into the plasma (McArdle et al., 2007). Chylomicrons, very low-density lipoprotein cholesterol (VLDL-C), low-density lipoprotein cholesterol (LDL-C), and highdensity lipoprotein (HDL-C) can all be characterized as lipoproteins (Durstine\& Moore, 2003). Approximately $85-92 \%$ of chylomicrons, which is the largest lipoprotein, are formed from triglycerides (Hussain, 2000). LDL-C is the primary transporter of cholesterol in the bloodstream, accounting for approximately $50-60 \%$ of cholesterol transported into the cell. Development of atherosclerotic plaque has been found to be due to an increase in LDL-C and a decrease in HDL-C as it contributes to cellular alterations of the inner walls of the arteries, which has been found to have a stronger association with coronary heart disease (CHD) than total cholesterol (Manson et al., 1992; Sharrett et al., 2001; Di Angelantonio et al., 2009; ACSM, 2010). The frequency of ischemic heart disease and CHD increases by $2 \%$ every time the total blood cholesterol increases by $1 \%$ (Castelli, 1988). HDL, which is small and rich in protein, binds to high-density cholesterol for the prevention of CHD.
Absorption of LDL-C at the body's receptor sites is inhibited by HDL-C as it contributes to the breakdown of the other lipoproteins. The transportation of cholesterol from the tissue and blood to the liver for removal out of the body or development into bile acids has been found to be due to HDL-C, which is believed to have an opposite relationship with CHD and has been described to counteract the development of CHD and prevent the occurrence of arteriosclerosis (Durstine \& Haskell 1994; Fielding \& Fielding, 1995; Shah et al., 2001; Sharrett et al., 2001; Dean et al., 2003; Curb et al., 2004; ACSM, 2010). HDL-C has been indicated to have the strongest lipid parameter for predicting and detecting CHD (Dean et al., 2003; ACSM, 2010). An increase in total serum cholesterol has been noted in diets relatively high in saturated fatty acids, which modify the lipoproteins to a more atherogenic profile, leading to a risk of CHD (Fletcher et al., 2005; Crouse et al.,2016). Unsaturated fatty acids may reduce CHD risk, if the saturated fatty acids are replaced in the diet, provided that the replaced unsaturated fatty acids are not from trans-fatty acids (Mozaffarian et al., 2006). According to Tektonidis et al., (2015), a diet relatively high in monounsaturated fatty acids oleic acid, promoted a lipid profile associated with a decrease in CHD. The American Heart Association previously recommended the use of a low-fat diet, especially low in saturated fatty acids, where calories from fat are replaced by carbohydrates. This recommendation was found to increase the risk of developing cardiovascular diseases (CVD), by increasing plasma triacylglycerol, lipoproteina and decrease HDL-C and LDL particle size (Hu et al., 1997; Muller et al., 2003; Gilmore et al., 2013). A re-evaluation of dietary saturated fatty acids was done after these findings, showing the effects it had on CVD (Gilmore et al., 2013). There are still restrictions in place on the consumption of saturated fatty acids in the diet, but the American Heart Association recognized that energy in the form of un- 
saturated fat in up to $40 \%$ of the diet was as healthy as low-fat diets (Kris-Etherton et al. 1999; Krauss et al. 2000).

\section{Exercise and Cholesterol}

Lower blood triglycerides, total cholester$\mathrm{ol}$ and LDL-C, and an increase HDL-C concentration has been observed in active men and women, compared to sedentary men and women (Crouse et al., 1997; Williams, 1997; Kelley et al., 2004; Greene et al., 2012). Increased blood HDL-C along with a reduction in triglycerides and LDL-C has been found after a single session of aerobic exercise in both trained and untrained men, where the effects lasted up to 48 hours after the exercise session was completed (Bounds et al., 2000; Grandjean et al., 2000). According to Crouse et al., (2016), a decrease in atherogenic lipid profile is associated with both exercise training and acute physical activity. Bassuk \& Manson, (2010), stated that the progression of CVD in women can be slowed by doing moderately intensive exercise for 30 minutes. A correlation has been noted between physical activity and HDL-C (Young et al., 1993). Higher HDL-C and total cholesterol and lower LDL-C and triglycerides have been found in women compared to men (Monda et al., 2009). With the onset of menopause, HDL-C concentration decreases in women. With postmenopausal decrease in HDL-C, an increase in CVD is seen and this is due to denser and smaller HDL particles, increase in LDL-C, total cholesterol, very low-density lipoprotein cholesterol, triglycerides, and BMI (Monda et al., 2009; Gilmore et al., 2013). Although there is a decrease of HDL-C after menopause, Weise et al., (2005), stated that even one session of physical activity has the potential to increase HDL-C in postmenopausal women.

\section{CONCLUSIONS}

Contemporary treatment of Type 2 diabetic patients requires a holistic approach and should include individually prescribed intake of anti-diabetic drugs, diet control, long term monitoring of blood glucose levels and other risk factors, and the effects of regular physical exercise programmes.

On the basis of the current review of the available accumulated research, we provided information about the impact of physical exercise and a low carbohydrate high fat diet in the treatment of diabetes. Further studies are needed and should be focused on implementing a comprehensive set of clinical tests (blood glucose, HbA1c, cholesterol, etc.), physical exercise protocols, performance tests and continuous monitoring the medication and the status of diabetic patients.

\section{REFERENCES}

Abete, I., Astrup, A., Martínez, J.A., Thorsdottir, I., \& Zulet, M.A. (2010). Obesity and the metabolic syndrome: role of different dietary macronutrient distribution patterns and specific nutritional components on weight loss and maintenance. Nutrition Reviews, 68: 214-231.

Ahmed, I., \& Goldstein, B. (2006). Diabetes mellitus. Clinics in Dermatology, 24(4):237-246.

American College of Sports Medicine. (2010). Guidelines for exercise testing and prescription -8 th ed. Philadelphia: Lippincot Williams and Wilkins. 46-233p.

American College of Sports Medicine. (2014). Guidelines for exercise testing and prescription - 9h ed. Philadelphia: Lippincot Williams and Wilkins. 278-280p.

Avenell, A., Broom, J., Brown, T.J., Poobalan, A., Aucott, L., Stearns, S.C., Smith, W.C., Jung, R.T., \& Grant, A.M. (2004). Systematic review of the long-term effects and economic consequences of treatments for obesity and implications for health improvements. Health Technology Assessment, 8(21): iii-iv, 1-182.

Awotidebe, T.O., Adedoyin, R.A., Afolabi, M.A., \& Opiyo, R. (2016). Knowledge, attitude and practice of exercise for plasma blood glucose control among patients with Type- 2 
diabetes. Diabetes \& Metabolic Syndrome. 10S:S1-6.

Bang, H.O., Dyerberg, J., \& Hjørne, N. (1976). The composition of food consumed by Greenland Eskimos. Acta Medica Scandinavica., 200: 69-73.

Bassuk, S., \& Manson, J. (2010). Physical activity and cardiovascular disease prevention in women: a review of the epidemiologic evidence. Nutrition, Metabolism and Cardiovascular Diseases, 20: 467-473.

Belue, R., Okoror, T. A., Iwelunmor, J., Taylor, K. D., Degboe, A. N., Agyemang, C., $\&$ Ogedegbe, G. (2009). An overview of cardiovascular risk factor burden in sub-Saharan African countries: a socio-cultural perspective. BMC Globalization and Health, 5:10.

Bertram, M.Y., Jaswal, A.V., van Wyk, V.P., Levitt, N.S., \& Hofman, K.J. (2013). The non-fatal disease burden caused by Type 2 diabetes in South Africa, 2009. Global Health Action, 24;6: 19244.

Boden, G., Sargrad, K., Homko, C., Mozzoli, M., \& Stein, T.P. (2005). Effect of a lowcarbohydrate diet on appetite, blood glucose levels, and insulin resistance in obese patients with type 2 diabetes. Annals of Internal Medicine, 142: 403-411.

Boulé, N.G., Kenny, G.P., Haddad, E., Wells, G.A., \& Sigal, R.J. (2003). Meta-analysis of the effect of structured exercise training on cardiorespiratory fitness in Type 2 diabetes mellitus. Diabetologia, 46(8):1071-1081.

Bounds, R.G., Martin, S.E., Grandjean, P.W., O’brien, B.C., Inman, C., \& Crouse, S.F. (2000). Diet and short-term plasma lipoprotein-lipid changes after exercise in trained men. International Journal of Sport Nutrition, 10: 114-127.

Bravata, D.M., Sanders, L., Huang, J., Krumholz, H.M., Olkin, I., \& Gardner, C.D. (2003). Efficacy and safety of low-carbohydrate diets: a systematic review. Journal of the American Medical Association, 289(14):1837-1850.

Bravata, D.M., Smith-spangler, C., Sun- daram, V., Gienger, A.L., Lin, N., Lewis, R., Stave, C.D., Olkin, I., \& Sirard, J.R. (2007). Using pedometers to increase physical activity and improve health: a systematic review. Journal of the American Medical Association, 21;298 (19): 2296-2304.

Carney, T.A., Guy, S.P., \& Helliwell, C.D. (2000). Seasonal variation in HbAlc in patients with Type 2 diabetes mellitus. Diabetic Medicine, 17: 554-555.

Castelli, W.P. (1988). Cholesterol and lipids in the risk of coronary artery disease. The Framingham heart study. Canadian Journal of Cardiology, 4: 5A-10A.

Chen, H.S., Jap, T.S., Chen, R.L. \& Lin, H.D. (2004). A prospective study of glycaemic control during holiday time in type 2 diabetic patients. Diabetes Care, 27: 326-330.

Church, T.S., Lamonte, M.J., Barlow, C.E., \& Blair, S.N. (2005). Cardiorespiratory fitness and body mass index as predictors of cardiovascular disease mortality among men with diabetes. Archives of Internal Medicine Journal, 165(18): 2114-2120.

Colberg, S.R., Albright, A.L., Blissmer, B.J., Braun, B., Chasan-taber, L., Fernhall, B., Regensteiner, J.G., Rubin, R.R., Sigal, R.J. American College of Sports Medicine \& American Diabetes Association. (2010). Exercise and Type 2 diabetes: American College of Sports Medicine and the American Diabetes Association: joint position statement. Exercise and Type 2 diabetes. Medicine \& Science in Sports \& Exercise, 42(12): 2282-2303.

Conn, V.S., Hafdahl, A.R., Mehr, D.R., Lemaster, J.W., Brown, S.A., \& Nielsen, P.J. (2007). Metabolic effects of interventions to increase exercise in adults with type 2 diabetes. Diabetologia, 50: 913-921.

Cornier, M.A., Donahoo, W.T., Pereira, R., Gurevich, I., Westergren, R., Enerback, S., Eckel, P.J., Goalstone, M.L., Hill, J.O., Eckel, R.H., \& Draznin, B. (2005). Insulin sensitivity determines the effectiveness of dietary macronutrient composition on weight loss in obese women. Obesity Research, 13: 703-709. 
Crouse, S.F., Green, J.S., Meade, T.H., Smith, D.R., \& Smith, S.B. (2016). Exercise raises high-density lipoprotein cholesterol in men after consumption of ground beef with a high but not low monounsaturated fatty acidsaturated fatty acid ratio. Nutrition Research, 36: 974-981.

Crouse, S.F., Obrien, B.C., Grandjean, P.W., Lowe, R.C., Rohack, J.J., \& Green, J.S. (1997). Effects of training and a single session of exercise on lipids and apolipoproteins in hypercholesterolemic men. Journal of Applied Physiology, 83: 2019-2028.

Crowther, N.J., \& Norris, S.A. (2012). The current waist circumference cut point used for the diagnosis of metabolic syndrome in subSaharan African women is not appropriate. PLoS One, 7(11): e48883.

Curb, J.D., Abbott, R.D., Rodriguez, B.L., Chen, R., Sharp, D.S., \& Tall, A.R. (2004). A prospective study of HDL-C and cholesterol ester transfer protein gene mutations and the risk of coronary heart disease in the elderly. The Journal of Lipid Research, 45: 948-953.

Daly, M.E., Paisey, R., Paisey, R., Millward, B.A., Eccles, C., Williams, K., Hammersley, S., Macleod, K.M., \& Gale, T.J. (2006). Short-term effects of severe dietary carbohydrate-restriction advice in type 2 diabetes - a randomized controlled trial. Diabetic Medicine, 23: 15-20.

Dasgupta, K., Chan, C., DA Costa, D., Pilote, L., de Civita, M., Ross, N., Strachan, I., Sigal, R., \& Joseph, L. (2007). Walking behaviour and glycemic control in type 2 diabetes: seasonal and gender differences - study design and methods. Cardiovascular Diabetology, 6: 1-11.

Dean, B.B., Borenstein, J.E., Henning, J.M., Knight, K., \& Merz, C.N. (2003). Can change in high-density lipoprotein cholesterol levels reduce cardiovascular risk? American Heart Journal, 147: 966-976.

De Greef, K., Deforche, B., Tudor-Locke, C., \& de Bourdeaudhuij, I. (2010). A cognitive-behavioural pedometer-based group in- tervention on physical activity and sedentary behaviour in individuals with Type 2 diabetes. Health Education Research, 25(5):724-736.

De Greef, K., Deforche, B., Tudor-Locke, C., \& De Bourdeaudhuij, I. (2011). Increasing physical activity in Belgian Type 2 diabetes patients: a three-arm randomized controlled trial. International Journal of Behavioral Medicine, 18(3):188-198.

Dela, F., Mikines, K.J., von Linstow, M., Secher, N.H., \& Galbo, H. (1992). Effect of training on insulin-mediated glucose uptake in human muscle. American Journal of Physiology, 263: E1134-1143.

Demol, S., Yackobovitch-gavan, M., Shalitin, S., Nagelberg, N., Gillon-keren, M., \& Phillip, M. (2009). Low-carbohydrate (low \& high-fat) versus high-carbohydrate low-fat diets in the treatment of obesity in adolescents. Acta Paediatrica, 98(2):346-351.

Di Angelantonio, E., Sarwar, N., Perry, P., Kaptoge, S., Ray, K.K., Thompson, A., Wood, A.M., Lewington, S., Sattar, N., Packard, C.J., Collins, R., Thompson, S.G., \& Danesh, J. (2009). Major lipids, apolipoproteins, and risk of vascular disease. Journal of the American Medical Association, 302: 1993-2000.

Donnelly, J.E., Blair, S.N., Jakicic, J.M., Manore, M.M., Rankin, J.W., Smith, B.K; \& American College of Sports Medicine. (2009). American College of Sports Medicine Position Stand. Appropriate physical activity intervention strategies for weight loss and prevention of weight regain for adults. Medicine \& Science in Sports \& Exercise, 41: 459-471.

Druet, C., Dabbas, M., Baltakse, V., Payen, C., Jouret, B., Baud C, Chevenne, D., Ricour, C., Tauber, M., Polak, M., Alberti, C., \& Levymarchal, C. (2006). Insulin resistance and the metabolic syndrome in obese French children. Clinical Endocrinology, 64:672-678.

Dube, L., van den Broucke, S., Dhoore, W., Kalweit, K., \& Housiaux, M. (2015). An Audit of Diabetes Self-Management Education Programs in South Africa. Journal of Public Health Research, 4:(581) 179-184. 
Durstine, J. L., \&. Haskell, W. L. (1994). Effects of exercise training on plasma lipids and lipoproteins. Exercise and Sports Science Reviews, 22: 477-521.

Durstine, J.L., \& Moore, G.E. (2003). ACSM's Exercise Management for Persons with Chronic Diseases and Disabilities, 2nd ed. American College of Sports Medicine.

EckeL, R.H., Jakicic, J.M., Ard, J.D., de Jesus, J.M., Miller, N.H., Hubbard, V.S., Lee, I., Lichtenstein, A.H., Loria, C.M., Millen, B.E., Nonas, C.A., Sacks, F.M., Smith, S.C. JR., Svetkey, L.P., Wadden, T.A., \& Yanovski, S.Z. (2014). 2013 AHA/ACC Guideline on Lifestyle Management to Reduce Cardiovascular Risk A Report of the American College of Cardiology/American Heart Association Task Force on Practice Guidelines. Circulation, 129: S76-99.

Fielding, C.J., \& Fielding, P.E. (1995). Molecular physiology of reverse cholesterol transport. Journal of Lipid Research, 36: 211228.

Flegal, K.M., Carroll, M.D., Ogden, C.L., \& Johnson, C.L. (2002). Prevalence and trends in obesity among US adults, 1999 - 2000. Journal of the American Medical Association, 288: 1723 - 1727.

Fletcher, B., Berra, K., Ades, P., Braun, L.T., Burke, L.E., Durstine, J.L., Fair, J.M., Fletcher, G.F., Goff, D., Hayman, L.L., Hiatt, W.R., Miller, N.H., Krauss, R., Kris-Etherton, P., Stone, N., Wilterdink, J., Winston, M; Council on Cardiovascular Nursing; Council on Arteriosclerosis, Thrombosis, and Vascular biology; Council on Basic Cardiovascular Sciences; Council on Cardiovascular Disease in the Young; Council on Clinical Cardiology; Council on Epidemiology and Prevention; Council on Nutrition, Physical Activity, and Metabolism; Council on Stroke; \& Preventive Cardiovascular Nurses Association. (2005). Managing abnormal blood lipids: a collaborative approach. Circulation, 112: 3184-3209.

Foster, G.D., Wyatt, H.R., Hill, J.O., Makris, A.P., Rosenbaum, D.L., Brill, C.,
Stein, R.I., Mohammed, B.S., Miller, B., Rader, D.J., Zemel, B., Wadden, T.A., Tenhave, T., Newcomb, C.W., \& Klein, S. (2010). Weight and metabolic outcomes after 2 years on a low-carbohydrate versus low-fat diet: a randomized trial. Annals of Internal Medicine, 3; 153: 147-157.

Foster, G.D., Wyatt, H.R., Hill, J.O., Mcguckin, B.G., Brill, C., Mohammed, S., Szapary, P.O., Rader, D. J., Edman, J.S., \& Klein, S. (2003). A randomized trial of a low-carbohydrate diet for obesity. The New England Journal of Medicine, 348; 21:2082-2090.

Gannon, M.C., \& Nuttall, F.Q. (2004). Effect of a high-protein, low-carbohydrate diet on blood glucose control in people with type 2 diabetes. Diabetes, 53: 2375-2382.

Gannon, M.C., Nuttall, F.Q., Saeed, A., Jordan, K., \& Hoover, H. (2003). An increase in dietary protein improves the blood glucose response in persons with type 2 diabetes. The American Journal of Clinical Nutrition, 78: 734-741.

Gikas, A., Sotiropoulos, A., Pastromas, V., Papazafiropoulou, A., Apostolou, O., \& Pappas, S. (2009). Seasonal variation in fasting glucose and HbA1c in patients with type 2 diabetes. Primary Care Diabetes, 3: 111-114.

Gilmore, L.A., Crouse, S.F., Carbuhn, A., Klooster, J., Calles, J.A., Meade, T., \& Smith, S.B. (2013). Exercise attenuates the increase in plasma monounsaturated fatty acids and high-density lipoprotein cholesterol but not high-density lipoprotein $2 \mathrm{~b}$ cholesterol caused by high-oleic ground beef in women. Nutrition Research, 33: 1003-1011.

Grandjean, P.W., Crouse, S.F., \& Rohack, J.J. (2000). Influence of cholesterol status on blood lipid and lipoprotein enzyme responses to aerobic exercise. Journal of Applied Physiology, 89: 472-480.

Greaves, C.J., Sheppard, K.E., Abraham, C., Hardeman, W., Roden, M., Evans, P.H., Schwarz, P. \& Image Study Group. (2011). Systematic review of reviews of intervention components associated with increased effec- 
tiveness in dietary and physical activity interventions. BMC Public Health, 18;11:119.

Greene, N.P., Martin, S.E., \& Crouse, S.F. (2012). Acute exercise and training alter blood lipid and lipoprotein profiles differently in overweight and obese men and women. Obesity, 20: 1618-1627.

Haimoto, H., Iwata, M., Wakai, K., \& Umegaki, H. (2008). Long-term effects of a diet loosely restricting carbohydrates on HbA1c levels, BMI and tapering of sulfonylureas in type 2 diabetes: a 2-year follow-up study. Diabetes Research and Clinical Practice, 79: 350-356.

Harrison, A.L., Shields, N., Taylor, N. F., \& Frawley, H. C. (2016). Exercise improves glycaemic control in women diagnosed with gestational 4 diabetes mellitus: a systematic review. Journal of Physiotherapy, 271: 1-9.

Haskell, W.L., Lee, I.M., Pate, R.R., Powell, K.E., Blair, S.N., Franklin, B.A., Macera, C.A., Heath, G.W., Thompson, P.D., \& Bauman, A. (2007). Physical activity and public health: updated recommendation for adults from the American College of Sports Medicine and the American Heart Association. Medicine \& Science in Sports \& Exercise, 39: 1423-1434.

Hjelm, K., \& Mufunda, E. (2010). Zimbabwean diabetics' beliefs about health and illness: an interview study. BMC International Health and Human Rights, 10:7.

Hu, F.B., Stampfer, M.J., Manson, J.E., Rimm, E., Colditz, G.A., Rosner, B.A., Hennekens, C.H., \& Willett, W.C. (1997). Dietary fat intake and the risk of coronary heart disease in women. The New England Journal of Medicine, 337: 1491-1499.

Hussain, M.M. (2000). A proposed model for the assembly of chylomicrons. Atherosclerosis, 148: 1-15.

Jue, T., Rothman, D.L., Shulman, G.I., Tavitian, B.A., Defronzo, R.A., \& Shulman, R.G. (1989). Direct observation of glycogen synthesis in human muscle with 13C NMR. Proceedings of the National Academy of Sci- ences U S A, 86: 4489-4491.

Kahn, C.R. (1994). Banting Lecture. Insulin action, diabetogenes, and the cause of Type II diabetes. Diabetes, 43(8):1066-1084.

Katan, M.B. (2006). Alternatives to lowfat diets. The American Journal of Clinical Nutrition, 83: 989-990.

Katzmarzyk, P.T., Leon, A.S., Wilmore, J.H., Skinner, J.S., Rao, D.C., Rankinen, T., \& Bouchard, C. (2003). Targeting the metabolic syndrome with exercise: evidence from the Heritage Family Study. Medicine \& Science in Sports \& Exercise, 35: 1703-1709.

Kawai, T. (2016). An attempt to design optimal personalized exercise prescriptions using the KEIO-SENIOR treadmill protocol for patients with Type 2 diabetes. Personalized Medicine Universe, 5: 27-31.

Kelley, G.A., Kelley, K.S., \& Tran, Z.V. (2004). Aerobic exercise and lipids and lipoproteins in women: a meta-analysis of randomized controlled trials. Journal of Women's Health, 13: 1148-1164.

Knowler, W.C., Barrett-Connor, E., Fowler, S.E., Hamman, R.F., Lachin, J.M., Walker, E.A., Nathan, D.M., \& Diabetes Prevention Program Research Group. (2002). Reduction in the incidence of type 2 diabetes with lifestyle intervention or metformin. The New England Journal of Medicine, 7; 346:393-403.

Korkiakangas, E.E., Alahuhta, M.A., \& Laitinen, J.H. (2009). Barriers to regular exercise among adults at high risk or diagnosed with Type 2 diabetes: a systematic review. Health Promotion International, 24(4):41627.

Krauss, R.M., Blanche, P.J., Rawlings, R.S., Firestorm, H.S., \& Williams, P.T. (2006). Separate effects of reduced carbohydrate intake and weight loss on atherogenic dyslipidemia. The American Journal of Clinical Nutrition, 83: 1025-1031.

Krauss, R.M., Deckelbaum, R.J., Ernst, N., Fisher, E., Howard, B.V., Knopp, R.H., Kotchen, T., Lichtenstein, A.H., Mcgill, H.C., Pearson, T.A., Prewitt, E., Stone, N.J., van 
Horn, L., and Weinberg, R. (1996). Dietary guidelines for healthy American adults: a statement for health professionals from the nutrition committee, American heart association. Circulation, 94: 1795-1800.

Krauss, R.M., Eckel, R.H., Howard, B., Appel, L.J., Daniels, S.R., Deckelbaum, R.J., Erdman, J.W. JR., Kris-Etherton, P., Goldberg, I.J., Kotchen, T.A., Lichtenstein, A.H., Mitch, W.E., Mullis, R., Robinson, K., Wylie-rosett, J., ST Jeor, S., Suttie, J., Tribble, D.L., \& Bazzarre, T.L. (2000). AHA Dietary Guidelines: revision 2000: A statement for healthcare professionals from the Nutrition Committee of the American Heart Association. Circulation, 102: 2284-2299.

Krieger, J.W., Sitren, H.S. Daniels, M.J. \& Langkamp-henken, B. (2006). Effects of variation in protein and carbohydrate intake on body mass and composition during energy restriction: a meta-regression 1. The American Journal of Clinical Nutrition, 83: 260-274.

Kris-Etherton, P.M., Pearson, T.A., Wan, Y., Hargrove, R.L., Moriarty, K., Fishell, V., \& Etherton, T.D. (1999). High-monounsaturated fatty acid diets lower both plasma cholesterol and triacylglycerol concentrations. The American Journal of Clinical Nutrition, 70: 1009-1015.

Krumm, E.M., Dessieux, O.L., Andrews, P., \& Thompson, D.L. (2006). The relationship between daily steps and body composition in postmenopausal women. Journal of Women's Health, 15: 202-210.

Kuenen, J.C., Borg, R., Kuik, D.J., Zheng, H., Schoenfeld, D., Diamant, M., Nathan, D.M., \& Heine, R.J. (2011). Does Glucose Variability Influence the Relationship Between Mean Plasma Glucose and HbA1c Levels in Type 1 and Type 2 Diabetic Patients? Diabetes Care, 34: 1843-1847.

Lamont, B. J., Waters, M. F., \& Andrikopoulos, S. (2016). A low-carbohydrate highfat diet increases weight gain and does not improve glucose tolerance, insulin secretion or $\beta$-cell mass in NZO mice. Nutrition \& Dia- betes, 6: 94.

León-Muñoz, L.M., Martínez-Gómez, D., Balboa-Castillo, T., López-García, E., Guallar-Castillón, P., \& Rodríguez-Artalejo, F. (2013). Continued sedentariness, change in sitting time, and mortality in older adults. Medicine \& Science in Sports \& Exercise, 48: 1501-1507.

Manson, J. E., Tosterson, H., Ridker, P. M., Satterfield, S., Hebert, P., G.T., O., Buring, J. E., \& Hennekens, C. H. (1992). The primary prevention of myocardial infarction. The New England Journal of Medicine, 326: 1406-1416.

Mayosi, B.M., Flisher, A.J., Lalloo, U.G., Sitas, F., Tollman, S.M., \& Bradshaw, D. (2009). The burden of non-communicable diseases in South Africa. Lancet, 374: 934-947.

McArdle, W.D., Katch, F.I., \& Katch, V.L. (2007). Exercise Physiology - Energy, Nutrition and Human Nutrition, 6th ed. Lippincot, Williams \& Wilkins.

McAuley, K.A., Hopkins, C.M., Smith, K.J., Mclay, R.T., Williams, S.M., Taylor, R.W., \& Mann, J.I. (2005). Comparison of high-fat and high-protein diets with a highcarbohydrate diet in insulin-resistant obese women. Diabetologia, 48: 8-16.

Mendenhall, E., \& Norris, S.A. (2015). Diabetes care among urban women in Soweto, South Africa: a qualitative study. BMC Public Health, 15: 1300.

Merino, J., Kones, R., Ferré, R., Plana, N., Girona, J., Aragonés, G., Ibarretxe, D., Heras, M., \& Masana, L. (2014). Low-Carbohydrate, High-protein, high-fat diet alters small peripheral artery reactivity in metabolic syndrome patients. Pub Med. 26: 58-65.

Miller, C.K., Headings, A., Peyrot, M., \& Nagaraja, H. (2011). A behavioural intervention incorporating specific glycaemic index goals improves dietary quality, weight control and glycaemic control in adults with type 2 diabetes. Public Health Nutrition, 14: 13031311.

Mithieux, G., Misery, P., Magnan, C., Pil- 
lot, B., Gautier-stein, A., Bernard, C., Rajas, F., \& Zitoun, C. (2005). Portal sensing of intestinal gluconeogenesis is a mechanistic link in the diminution of food intake induced by diet protein. Cell Metabolism, 2(5):321-329.

Monda, K.L., Ballantyne, C.M., \& North, K.E. (2009). Longitudinal impact of physical activity on lipid profiles in middle-aged adults: the atherosclerosis risk in communities study. The Journal of Lipid Research, 50: 1685-1691.

Mozaffarian, D., Katan, M.B., Ascherio, A., Stampfer, M.J., \& Willett, W.C. (2006). Medical progress - trans fatty acids and cardiovascular disease. The New England Journal of Medicine, 354: 1601-1613.

Muller, H., Lindman, A.S., Brantsaeter, A.L., \& Pedersen, J.I. (2003). The serum LDL/HDL cholesterol ratio is influenced more favourably by exchanging saturated with unsaturated fat than by reducing saturated fat in the diet of women. Journal of Nutrition, 133: 78-83.

Murphy, K., Chuma, T., Mathews, C., Steyn, K., \& Levitt, N. (2015). A qualitative study of the experiences of care and motivation for effective self-management among diabetic and hypertensive patients attending public sector primary health care services in South Africa. BMC Health Services Research, 15:303.

Nanri, A., Mizoue, T., Kurotani, K., Goto, A., Oba, S., Noda, M., Sawada, N., Tsugane, S; Japan Public Health Center-Based Prospective Study Group. (2015). Low-Carbohydrate Diet and Type 2 Diabetes Risk in Japanese Men and Women: The Japan Public Health CenterBased Prospective Study. Plos one. 1: http:// dx.doi.org/10.1371/journal.pone.0118377.

Noakes, T. (2017). Evidence that supports the prescription of low-carbohydrate high-fat diets: A Narrative Review. British Journal of Sports Medicine. 51: 133-139.

Noakes, T., Creed, S., Proudfood, J., \& Grier, D. (2013). The real meal revolution. Changing the world. One meal at a time. Qui- vertree Publications, pg. 18

Nordmann, A.J., Nordmann, A., Briel, M., Keller, U., Yancy, W.S. JR., Brehm, B.J., \& Bucher, H.C. (2006). Effects of low-carbohydrate vs low-fat diets on weight loss and cardiovascular risk factors: a meta-analysis of randomized controlled trials. Archives of internal medicine, 166: 285-293.

Ozougwu, O. (2013). The pathogenesis and pathophysiology of Type-1 and Type-2 diabetes mellitus. Journal of Physiology and Pathophysiology, 4: 46-57.

Parker, B., Noakes, M., Luscombe, N., \& Clifton, P. (2002). Effect of a high-protein, high-monounsaturated fat weight loss diet on glycemic control and lipid levels in Type 2 diabetes. Diabetes Care, 25: 425-430.

Peer, N., Steyn, K., Lombard, C., Lambert, E.V., Vythilingum, B., \& Levitt, N.S. (2012). Rising diabetes prevalence among urbandwelling black South Africans. PLoS One. 7(9):e43336.

Peter, J.S., \& Sabina, E.P. (2016). Global current trends in natural products for diabetes management: a review. International Journal of Pharmacy and Pharmaceutical Sciences, 8, (4): 20-28.

Pittas, A.G., Das, S.K., Hajduk, C.L., Golden, J., Saltzman, E., Stark, P.C., Greenberg, A.S., \& Roberts, S.B. (2005). A lowglycemic load diet facilitates greater weight loss in overweight adults with high insulin secretion but not in overweight adults with low insulin secretion in the CALERIE Trial. Diabetes Care, 28: 2939-2941.

Pronk, N.P., \& Remington, P.L. (2015). Combined diet and physical activity promotion programs for prevention of diabetes: Community preventive services task force recommendation statement. Annals of Internal Medicine, 163(6): 465-468.

Psaltopoulou, T., Ilias, I., \& Alevizaki, M. (2010). The role of diet and lifestyle in primary, secondary, and tertiary diabetes prevention: a review of meta-analyses. Review of Diabetic Studies, 7(1): 26-35. 
Reaven, G.M. (2011). Insulin resistance: the link between obesity and cardiovascular disease. Medical Clinics of North America, 95: 875-892.

Revdal, A., Hollekim-strand, S.M., \& Ingul, C.B. (2016). Can Time Efficient Exercise Improve Cardiometabolic Risk Factors in Type 2 Diabetes? A Pilot Study. Journal of Sports Science and Medicine, 15(2): 308-313.

Rossen, J., Yngue, A., Hagströmer, M., Brismar, K., Ainsworth, B.E., Iskull, C., Möller, P., \& Johansson, U. (2015). Physical activity promotion in the primary care setting in pre- and Type 2 diabetes - the Sophia step study, an RCT. BMC Public Health, 15: 647657.

Rydén, L., Grant, P.J., Anker, S.D., Berne, C., Cosentino, F., Danchin, N., Deaton, C., Escaned, J., Hammes, H.P., Huikuri, H., Marre, M., Marx, N., Mellbin, L., Ostergren, J., Patrono, C., Seferovic, P., Uva, M.S., Taskinen, M.R., Tendera, M., Tuomilehto, J., Valensi, P., Zamorano, J.L., Esc Committee for Practice Guidelines (CPG),. Zamorano, J.L., Achenbach, S., Baumgartner, H., Bax, J.J., Bueno, H., Dean, V., Deaton, C., Erol, C., Fagard, R., Ferrari, R., Hasdai, D., Hoes, A.W., Kirchhof, P., Knuuti, J., Kolh, P., Lancellotti, P., Linhart, A., Nihoyannopoulos, P., Piepoli, M.F., Ponikowski, P., Sirnes, P.A., Tamargo, J.L., Tendera, M., Torbicki, A., Wijns, W., Windecker, S. Document Reviewers., DE Backer, G., Sirnes, P.A., Ezquerra, E.A., Avogaro, A., Badimon, L., Baranova, E., Baumgartner, H., Betteridge, J., Ceriello, A., Fagard, R., Funckbrentano, C., Gulba, D.C., Hasdai, D., Hoes, A.W., Kjekshus, J.K., Knuuti, J., Kolh, P., Lev, E., Mueller, C., Neyses, L., Nilsson, P.M., Perk, J., Ponikowski, P., Reiner, Z., Sattar, N., Schächinger, V., Scheen, A., Schirmer, H., Strömberg, A., Sudzhaeva, S., Tamargo, J.L., Viigimaa, M., Vlachopoulos, C., \& Xuereb, R.G. (2013). ESC Guidelines on diabetes, pre-diabetes, and cardiovascular diseases developed in collaboration with the EASD: The Task Force on diabetes, pre-diabetes, and car- diovascular diseases of the European Society of Cardiology (ESC) and developed in collaboration with the European Association for the Study of Diabetes (EASD). European Heart Journal, 34(39): 3035-3087.

Sacks, F.M., Bray, G.A., Carey, V.J., Smith, S.R., Ryan, D.H., Anton, S.D., Mcmanus, K., Champagne, C.M., Bishop, L.M., Laranjo, N., Leboff, M.S., Rood, J.C., de Jonge, L., Greenway, F.L., Loria, C.M., Obarzanek, E., \& Williamson, D.A. (2009). Comparison of Weight-Loss Diets with Different Compositions of Fat, Protein, and Carbohydrates. The New England Journal of Medicine, 360: 859873.

Santos, J.M., Ribeiro, S.B., Gaya, A.R., Appell, H.J., \& Duarte, J.A. (2008). Skeletal muscle pathways of contraction-enhanced glucose uptake. International Journal of Sports Medicine, 29:785-794.

Shah, P.K., Kaul, S., Nilsson, J., \& Cercek, B. (2001). Exploiting the vascular protective effects of high-density lipoprotein and its apolipoproteins: an idea whose time for testing is coming, part I. Circulation, 104: 2376-2383.

Sharrett, A.R., Ballantyne, C.M., Coady, S.A., Heiss, G., Sorlie, P.D., Catellier, D., \& Patsch, W; \& Atherosclerosis Risk in Communities Study Group. (2001). Coronary heart disease prediction from lipoprotein cholesterol levels, triglycerides, lipoprotein, apolipoproteins A-I and B, and HDL density sub fractions: The Atherosclerosis Risk in Communities (ARIC) Study. Circulation, 104: 1108-1113.

Shulman, G.I., Rothman, D.L., Jue, T., Stein, P., Defronzo, R.A., \& Shulman, R.G. (1990). Quantitation of muscle glycogen synthesis in normal subjects and subjects with non-insulin-dependent diabetes by $13 \mathrm{C}$ nuclear magnetic resonance spectroscopy. The New England Journal of Medicine, 25; 322: 223-228.

Sigal, R.J., Kenny, G.P., Wasserman, D.H., Castaneda-Sceppa, C., \& White, R.D. (2006). Physical Activity/Exercise and Type 2 Diabe- 
tes A consensus statement from the American Diabetes Association. Diabetes Care, 29: 6.

South Africa Mining Laws and Regulations Handbook. (2014). International Business Publications, USA ISBN 1-4330-7822-8. 1: Strategic Information and Basic Law.

Steinberger, J., Daniels, S.R., American Heart Association Atherosclerosis, Hypertension, and Obesity in the Young Committee (Council on Cardiovascular Disease in the Young)., \& American Heart Association Diabetes Committee (Council on Nutrition, Physical Activity, and Metabolism). (2003). Obesity, insulin resistance, diabetes, and cardiovascular risk in children: an American Heart Association scientific statement from the Atherosclerosis, Hypertension, and Obesity in the Young Committee (Council on Cardiovascular Disease in the Young) and the Diabetes Committee (Council on Nutrition, Physical Activity, and Metabolism). Circulation. 107(10): 1448-1453.

Stratton, I.M., Adler, A.I., Neil, H.A., Matthews, D.R., Manley, S.E. Cull, C.A., Hadden, D. Turner, R. C. \& Holman, R. R. (2000). Association of glycaemia with macrovascular and microvascular complications of type 2 diabetes (UKPDS 35): prospective observational study. BMJ, 321: 405-412.

Tektonidis, T.G., Akesson, A., Gigante, B., Wolk, A., \& Larsson, S.C. (2015). A Mediterranean diet and risk of myocardial infarction, heart failure and stroke: a population-based cohort study. Atherosclerosis, 243: 93-98.

Thomas, N., Alder, E., \& Leese, G.P. (2004). Barriers to physical activity in patients with diabetes. Postgraduate Medical Journal, 80(943): 287-291.

Tien, K.J., Yang, C.Y., Weng, S.F., Liu, S.Y., Hsieh, M.C., \& Chou, C.W. (2016). The impact of ambient temperature on HbAlc in Taiwanese type 2 diabetic patients: The most vulnerable subgroup. Journal of the Formosan Medical Association, 115: 343-349.

Tudor-Locke, C., Craig, C.L., Brown, W.J., Clemes, S.A., de Cocker, K., Giles-Corti, B.,
Hatano, Y., Inoue, S., Matsudo, S.M, Mutrie, N., Oppert, J.M., Rowe, D.A., Schmidt, M.D., Schofield, G.M., Spence, J.C., Teixeira, P.J., Tully, M.A., \& Blair, S.N. (2011). How many steps/day are enough? For adults. International Journal of Behavioral Nutrition and Physical Activity, 28; 8:79.

Turcotte, L.P., \& Fisher, J.S. (2008). Skeletal muscle insulin resistance: roles of fatty acid metabolism and exercise. Journal of the American Physical Therapy Association, 88: 1279-1296.

Umpierre, D., Ribeiro, P.A., Kramer, C.K., Leitão, C.B., Zucatti, A.T., Azevedo, M.J., Gross, J.L., Ribeiro, J.P., \& Schaan, B.D. (2011). Physical activity advice only or structured exercise training and association with HbA1c levels in Type 2 diabetes: a systematic review and meta-analysis. Journal of the American Medical Association, 305(17): 1790-1799.

Unwin, N., Gan, D., \& Whiting, D. (2010). The IDF Diabetes Atlas: providing evidence, raising awareness and promoting action. Diabetes Research and Clinical Practice, 87(1):2-3.

Volek, J.S., \& Westman, E.C. (2002). Verylow-carbohydrate weight-loss diets revisited. Cleveland Clinic Journal of Medicine, 69(11): 849, 853, 856-8 passim.

Watson, N.A., Dyer, K.A., Buckley, J.D., Brinkworth, G.D., Coates, A.M., Parfitt, G., Howe, P.R., Noakes, M., Dye, L., Chadwick, H., \& Murphy, K.J. (2015). A randomised trial comparing low-fat diets differing in carbohydrate and protein ratio, combined with regular moderate intensity exercise, on glycaemic control, cardiometabolic risk factors, food cravings, cognitive function and psychological wellbeing in adults with type 2 diabetes: Study protocol. Contemporary Clinical Trials, 45: 217-225.

Wei. M., Gibbons, L.W., Kampert, J.B., Nichaman, M.Z., \& Blair, S.N. (2000). Low cardiorespiratory fitness and physical inactivity as predictors of mortality in men with 
Type 2 diabetes. Annals of Internal Medicine, 132(8): 605-611.

Wei, M., Gibbons, L.W., Mitchell, T.L., Kampert, J.B., Lee, C.D., \& Blair, S.N. (1999). The association between cardiorespiratory fitness and impaired fasting glucose and Type 2 diabetes mellitus in men. Annals of Internal Medicine, 130(2): 89-96.

Weise, S.D., Grandjean, P.W., Rohack, J.J., Womack, J.W., \& Crouse, S.F. (2005). Acute changes in blood lipids and enzymes in postmenopausal women after exercise. Journal of Applied Physiology, 99: 609-615.

Whiting, D.R., Guariguata, L., Weil, C., \& Shaw, J. (2011). IDF Diabetes atlas: global estimates of the prevalence of diabetes for 2011 and 2030. Diabetes Research and Clinical Practice, 94: 311-321.

Wild, S., Roglic, G., Green, A., Sicree, R., \& King, H. (2004). Global prevalence of diabetes: estimates for the year 2000 and projections for 2030. Diabetes Care, 27: 1047-1053.

Williams, P.T. (1997). Relationship of distance run per week to coronary heart disease risk factors in 8283 male runners - the national runners' health study. Archives of Internal Medicine Journal, 157: 191-198.

Winnick, J.J., Sherman, W.M., Habash,
D.L., Stout, M.B., Failla, M.L., Belury, M.A., \& Schuster, D.P. (2008). Short-term aerobic exercise training in obese humans with Type 2 diabetes mellitus improves whole-body insulin sensitivity through gains in peripheral, not hepatic insulin sensitivity. The Journal of Clinical Endocrinology \& Metabolism, 93: 771-778.

Yancy, W.S. JR., Olsen, M.K., Guyton, J.R., Bakst, R.P., \& Westman, E.C. (2004). A low-carbohydrate, ketogenic diet versus a low-fat diet to treat obesity and hyperlipidemia: a randomized, controlled trial. Annals of Internal Medicine, 140: 769-777.

Young, D.R., Haskell, W.L., Jatulis, D.E., \& Fortmann, S.P. (1993). Associations between changes in physical activity and risk factors for coronary heart disease in a community-based sample of men and women: The Stanford Five-City Project. American Journal of Epidemiology, 138: 205-216.

Zhang, Y., Hu, G., Yuan, Z., \& Chen, L. (2012). Glycosylated haemoglobin in relationship to cardiovascular outcomes and death in patients with Type 2 diabetes: a systematic review and meta-analysis. PLoS One, 7(8): e42551.

\section{Corresponding author:}

\section{Gerrit Jan Breukelman}

Department of Human Movement Science,

University of Zululand, KwaDlangezwa 3886, South Africa; E-mail: breukelmang@unizulu.ac.za 